\title{
THE COUNCIL OF BRITISH OPHTHALMOLOGISTS
}

To the Editors of THE BRITISH JOURNAL OF OPHTHALMOLOGY.

DEAR SIRS,-The Council desire me to call attention to the paragraph in the Annual Report (a copy of which appears in this issue of your Journal) which states that "A Sub-Committee has been set up to consider the advisability of enlarging the scope and widening the activities of the Council of British Ophthalmologists, and to make concrete proposals to the Council."

This paragraph excited considerable interest and discussion at the Annual Meeting held on May 1, and it was thought that others not present at that Meeting might wish to express their views and to make suggestions. I am directed to request that any such should communicate at once with the Convener and Secretary:

Miss Ida Mann, F.R.C.S.,

The Nuffield Laboratory of Ophthalmology,

The Eye Hospital, Walton Street, Oxford.

It is proposed that the Sub-Committee's Report be considered at a special Meeting to be'called before the next Annual Meeting, possibly at the time of this year's Oxford Congress in July.

I have the honour to be, Sirs,

\section{Your obedient Servant,}

FranK W. LAW, Hon Secretary.

36. Devonshire Place,

LONDON, W.1

May 6, 1943.

\section{OBITUARY \\ LUTHER PETER}

DR. LUTHER PETER died recently at the age of 73 as the result of an impaction of a gallstone in the common bile duct. He was well known to British ophthalmologists by his disquisitions on perimetry and on squint at the Oxford Congresses of 1920 and 1932, and to those who attended the International Congress of Ophthalmology at Washington in 1922 as its Secretary.

Peter's earliest interest was in neurology, from which he gravitated into ophthalmology, in which branch of medicine and surgery he 
had held professional posts at the University of Pennsylvania. He was President of the American Academy of Ophthalmology and Oto-laryngology in 1928.

His book on perimetry appeared in four editions and that on the extra-ocular muscles in two editions. His widow survives him.

A. F. Maccallain.

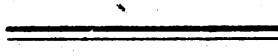

NOTES

Death

As we go to press, we learn with very great regret of the death of Mr. Leslie Paton. A full notice will appear in our next number.

- Post-graduate Lectures in Ophthalmology at Glasgow

THE following lectures have been arranged in the Department of Ophthalmology, University of Glasgow.

May 5, Dr. A. GARRow.-"The problem of the young myope." May-12, Dr. C. W. GRAhaM.- "Ophthalmic experiences in the Middle East.

May 19, Dr. JAMES Hill.- “ Observation on ocular tumours." May 26, Dr. George BeLl.-"The visual physiology of the cinema."

June 2, Dr. I. S. MACGREGor.-“"Toxic blindness."

* We regret that this note reached us too late for inclusion last month-EDITORS.

Royal Society of Medicine
THE last meeting of the Section of Ophthalmology during the session 1942.43 will be held as follows :-

Friday, June 11 , at 4.30 p.m., Cases.

At 5 p.m., Lieut.-Col. Derrick Vail, U.S.A., M.C., paper on "choroido-retinitis associated with toxo-plasma."

The annual business meeting will follow the paper.

Special Notice

WE are asked by the Ministry of Information to state that the fact that goods made of raw materials in short supply owing to war conditions are advertised in this journal should not be taken as an indication that they are necessarily available for export. 